\title{
Percepção de Pacientes sobre a Internação em um Hospital Universitário: Implicações para o Ensino Médico
}

PALAVRAS-CHAVE

- Educação Médica;

- Relações Médico-Paciente;

- Psicologia Médica.

KEY-WORDS

- Education, Medical;

- Physician-Patient Relations;

- Psychology, Medical.

Recebido em: 03/11/2005

Reencaminhado em: 07/04/2006

Aprovado em: 21/06/2006

$42 \mid \frac{\text { REVISTA BRASILEIRA DE EDUCAÇÃO MÉDICA }}{30 \text { (2) : } 42 \text { - } 48 ; 2006}$
Patients' Perception of Hospitalization in a
University Hospital: Implications for Medical
Teaching

Andrea Christina Cortopassi ${ }^{1}$

Maria Cristina Pereira Lima ${ }^{2}$ Irio José Gonçalves ${ }^{3}$

\section{RESUMO}

Objetivo: Avaliar a percepção dos pacientes quanto à relação estabelecida com profissionais e alunos durante internação no Hospital das Clínicas da Faculdade de Medicina de Botucatu (FMB-Unesp). Metodologia: Trata-se de um estudo observacional, no qual as informações foram colhidas por meio de entrevistas para obter dados sobre as internações, tendo sido realizado também grupo focal com pacientes de uma das enfermarias. Resultados: A internação foi avaliada como boa e ótima pela maior parte dos pacientes, tanto nas respostas às entrevistas quanto no grupo focal. As poucas queixas que surgiram foram dirigidas principalmente à visita médica. Conclusões: Embora as avaliações tenham sido positivas, os pacientes se mostraram ambivalentes em relação à visita médica. Diretrizes que norteiem sua realização são necessárias para que a mesma preserve seu papel didático sem prejuízo para o paciente. Estratégias institucionais de avaliação contínua devem ser desenvolvidas, especialmente em serviços universitários, aliando metodologias quantitativas e qualitativas.

\begin{abstract}
Objective: Evaluate how inpatients perceive the relationships established with professionals and students during their stay in the Botucatu Medical School Hospital (FMB-Unesp). Methodology: Observational study, in which information was collected through interviews for obtaining data about the hospitalization and using the technique of a focus group with patients from one of the hospital wards. Results: The hospitalization was evaluated as good or excellent by the greater part of patients both in the interviews and in the focal group. The few complaints that arose referred mainly to the doctors' rounds. Conclusions: Although the evaluations were positive, the patients were ambivalent in relation to the doctors' rounds. Guidelines providing orientation for how these rounds should be performed are necessary so that they can preserve their didactic role without affecting the patient. Institutional strategies for continuous quantitative and qualitative evaluation should be developed, especially in university services.
\end{abstract}

\footnotetext{
Departamento de Cirurgia e Traumatologia, Faculdade de Medicina de Botucatu, Universidade Estadual Paulista, Botucatu, São Paulo, Brasil. ${ }^{2}$ Departamento de Neurologia e Psiquiatria, Faculdade de Medicina de Botucatu, Universidade Estadual Paulista, Botucatu, São Paulo, Brasil. ${ }^{3}$ Departamento de Cirurgia e Ortopedia, Faculdade de Medicina de Botucatu, Universidade Estadual Paulista, Botucatu, São Paulo, Brasil.
} 


\section{INTRODUÇÃO}

A necessidade de humanização da prática médica desde a formação profissional há muito tem sido salientada, tanto na imprensa leiga quanto na literatura especializada ${ }^{1}$, passando também pelas instituições de ensino, Conselhos de Medicina e instâncias governamentais. Com a promulgação das Diretrizes Curriculares Nacionais para o Curso de Graduação em Medicina $^{2}$, em 2001, esta discussão ganhou novo fôlego. As competências definidas como necessárias à formação do profissional abarcam habilidades, aspectos cognitivos e atitudes, estas últimas marcadas pela exigência de uma atuação médica humanista e pautada em princípios éticos. Sendo o ensino médico essencialmente prático, é imprescindível que, durante sua formação, o estudante interaja com pacientes e usuários, observando como o fazem os professores, aprendendo e modelando sua relação com o paciente quando estiver formado $3-6$.

Rocco $^{7}$ realizou um estudo qualitativo das relações entre estudantes de Medicina e pacientes, que se tornou um clássico para os interessados pelo tema. Segundo esse estudo, os pacientes que procuram os serviços universitários são, em geral, pessoas com poucos recursos econômicos e, conseqüentemente, com poucas opções para buscar serviços de saúde. No ensino de Semiologia, o autor convivia com o relato dos alunos que acreditavam incomodar os pacientes ao examiná-los exaustivamente - crença confirmada pelos pacientes que participavam dos grupos operativos. Assim sendo, a hipótese do autor era a de que, ao entrevistar os pacientes individualmente, as queixas deles seriam ratificadas. No entanto, isto não ocorreu.

Chama a atenção a ausência de críticas do paciente, examinado por estudantes que podem cometer erros devido a sua suposta precária formação, além do desconforto de ser examinado várias vezes. Não há correspondência entre o sentimento do estudante que se considera usando o paciente e o deste, que não se sente usado (grifo do autor). Isto contradiz resultados obtidos em entrevistas com os próprios alunos e durante grupos operativos no hospital universitário, onde os pacientes se queixam deste fato. A resposta pode esconder o medo de ser discriminado pela instituição como revide à crítica ou funcionar como penitência por tudo de bom que está recebendo, ao assinalar os cuidados e o conforto que esses hospitais, de regra, proporcionam.

Assim, pacientes de serviços universitários, pelas condições socioeconômicas a que estão expostos, parecem tender a não se queixar dos atendimentos por alunos quando entrevis- tados isoladamente, em contraste com o que ocorre quando se encontram em grupo.

"Prestar um atendimento humanizado, marcado pelo bom relacionamento pessoal e pela dedicação de tempo e atenção necessários" ${ }^{\prime \prime}$, mais do que um requisito na formação do médico, é um preceito ético fundamental ao exercício da Medicina. Na formação médica, o impacto dos conceitos ministrados em cursos isolados de Psicologia Médica se somará ao cotidiano nos serviços de saúde, produzindo, ao final, modelos para os profissionais em formação ${ }^{9}$. Saber o que pensam e sentem os pacientes a respeito de seu contato com os alunos e profissionais é importante na formulação das atividades práticas desenvolvidas pelas escolas médicas.

Apesar da ampliação dos cenários de ensino, o hospital ainda é um espaço importante, no qual os alunos encontrarão portadores de patologias graves, muitas vezes separados de seus familiares e destituídos de sua subjetividade.

Dada a relevância de ampliar a discussão do hospital como local de ensino e investigar a relação de pacientes com profissionais e alunos neste cenário, elaborou-se um estudo com pacientes internados nas enfermarias do Hospital das Clínicas da Faculdade de Medicina de Botucatu, Unesp (HC-FMB). Este estudo buscou apreender a percepção de pacientes internados em enfermarias do HC-FMB sobre a relação estabelecida com os profissionais e acadêmicos durante o período de internação, refletindo sobre o ensino médico a partir dos resultados observados.

\section{MATERIAL E MÉTODOS}

Desenho: Trata-se de um estudo de caso, de natureza qualitativa, conduzido a partir da realização de grupo focal e de entrevistas com pacientes internados em duas enfermarias do Hospital das Clínicas da Faculdade de Medicina de Botucatu.

Local: Foram escolhidas as duas maiores enfermarias do Hospital das Clínicas da Faculdade de Medicina de Botucatu, sendo uma clínica e uma cirúrgica, ambas com grande fluxo de alunos e residentes ao longo do ano. As entrevistas ocorreram entre março e abril na enfermaria cirúrgica e entre maio e junho na enfermaria clínica.

Sujeitos: Pacientes internados nas enfermarias referidas, que se encontravam de alta e que consentiram em ser entrevistados ou participar do grupo focal.

Participantes da pesquisa: Participaram da pesquisa pacientes que receberam alta médica das enfermarias, escolhidos aleatoriamente. Optou-se por pacientes com alta supondo-se que estes deveriam estar em melhor estado físico, tendo condições de decidir sobre sua participação. Essa escolha poderia 
também minimizar o risco de que os pacientes não respondessem as questões por "medo" de possíveis represálias da instituição, como sugere $\operatorname{Rocco}^{7}$, e também por terem uma avaliação mais completa do período de internação.

Instrumento: Foi utilizado um roteiro especialmente elaborado pelas autoras com questões fechadas e abertas sobre aspectos sociodemográficos e sobre a internação do paciente, incluindo o nome dos profissionais envolvidos com o cuidado do paciente, no total de 33 itens (Quadro 1). Ao final do questionário, a entrevistadora verificava no prontuário as informações sobre diagnóstico, os nomes dos profissionais que cuidaram do paciente e o tempo de internação.

Grupo focal: Tendo em vista as observações de Rocco sobre as diferenças que os pacientes apresentam quando entrevistados individualmente e em grupo, optou-se pela realização de grupo focal na enfermaria cirúrgica. Para a realização do grupo focal, coordenado pelas autoras, as perguntas feitas nas entrevistas foram utilizadas como roteiro. Os grupos focais constituem um recurso particularmente apropriado para pesquisas qualitativas, possibilitando que os participantes se sintam mais estimulados a expressar suas opiniões do que quando entrevistados isoladamente, pois interagem também entre si e não apenas com o moderador do grupo ${ }^{10}$.

Procedimento de entrevista: Os dias para entrevista foram sorteados, sendo também sorteados os pacientes, na eventualidade de haver mais de um sujeito de alta. A entrevistadora se apresentava ao paciente sorteado, prestando esclarecimentos sobre a pesquisa, convidando-o a participar e entregando o termo de consentimento livre após esclarecimento, em caso afirmativo.

Procedimento de análise dos dados: As questões fechadas foram digitadas em planilha eletrônica do programa Excel, obtendo-se freqüência e percentagens das variáveis, e, quando cabíveis, medidas de tendência central e variabilida$\mathrm{de}^{11}$. As questões abertas foram submetidas a pré-análise, consistindo em leitura flutuante realizada independentemente pelas autoras, com o objetivo de identificar os temas predominantes.

Considerações éticas: $\mathrm{O}$ projeto foi encaminhado ao Comitê de Ética em Pesquisa da Faculdade de Medicina de Botucatu, tendo recebido parecer favorável.

\section{RESULTADOS}

Grupo focal: O grupo foi realizado na enfermaria cirúrgica, coordenado pelas autoras, com a participação de sete pacientes, sendo quatro mulheres e três homens, não tendo havido recusas em participar do grupo. Quando indagados a respeito da internação, todos referiram gratidão pela assistência, sendo que as raras queixas foram seguidas de tentativas de minimização, ao compararem com o atendimento recebido em outros locais ou recordarem situações em que o hospital salvara a vida de familiares. Pacientes que haviam sido submetidos a intervenções cirúrgicas nesta internação espontaneamente se referiam a estes procedimentos elogiando o atendimento recebido e justificando a avaliação pelo "bom" resultado obtido na cirurgia.

As principais queixas foram relacionadas ao espaço físico e ao ambiente hospitalar, como, por exemplo, não conseguir dormir à noite devido à luz acesa ou ao barulho. Houve também queixas relacionadas à falta de informação ou esclarecimento a respeito de suas doenças, cirurgias, procedimentos e também à demora para ser atendido no pronto-socorro. Surgiu, explicitamente, a preocupação de que as queixas não prejudicassem o atendimento atual e futuro no HC, mesmo após as coordenadoras já terem esclarecido sobre a natureza da atividade e a garantia de sigilo.

Os pacientes interpretaram as perguntas rotineiras da enfermagem em relação a sono e alimentação como se fossem preocupações pessoais dos profissionais com seu bemestar. Alguns pacientes aproveitaram o espaço para fazer reivindicações, como, por exemplo, aumentar o horário de visitas e não ficar acamado em macas no pronto-socorro. Embora reconhecessem o tratamento como gentil, ninguém se referiu aos cuidadores pelo nome, aqui incluídos todos os profissionais de enfermagem, alunos, docentes e residentes.

As moças se preocupam com a gente. Perguntam se a gente dormiu bem, se comeu a comida, se foi ao banheiro... Aqui é bom de ficar. Lá no pronto socorro é que é muito ruim... muito cheio. Aqui a única coisa ruim é que o horário das visitas é muito pequeno... Outra coisa é que o tempo não passa...

Em relação à visita médica, todos disseram que não compreendiam o que era falado e que se tratava de uma situação desagradável, porém afirmavam que os alunos precisam das aulas para aprender.

Quando junta todo mundo no quarto e ficam falando as coisas é ruim porque a gente não entende muito bem... Mas a gente sabe que precisa para os estudantes aprenderem, né?

Questionados sobre a relação com os demais pacientes, referiram que só conheciam aqueles que estavam no mesmo quarto, sendo recordado por uma paciente que isto era diferente na Pediatria, pois, quando seu filho esteve internado, ela e o menino tinham contato com outras pessoas, o que considerava uma boa experiência. 
Quando meu filho ficou internado na Pediatria, a gente ía no parque, almoçava com as outras mães e conversava um pouco... Aqui a gente fica mais sozinha, cada um no seu quarto... Eu só conhecia a senhora que está no mesmo quarto que eu...

Entrevistas: Não houve recusas em participar, sendo que 25 pessoas responderam ao questionário, 11 delas na enfermaria clínica e os demais na enfermaria cirúrgica. Houve discreto predomínio do sexo feminino (14), de pessoas em união consensual (15), com mediana de idade de 47 anos (variando de 18 a 77). A escolaridade variou de nenhuma a 12 anos completos, com um quarto do grupo possuindo escolaridade menor do que 1 ano. Metade possuía vínculo empregatício, mas a maior parte (17) possuía renda per capita menor do que um salário mínimo. Apenas um paciente possuía convênio médico.

A mediana do tempo de internação foi de 5 dias, variando de 2 a 20 dias. Quanto ao modo como avaliaram o período de internação, observou-se que todos qualificaram o período como bom ou ótimo. Do mesmo modo, a quase totalidade dos pacientes referiu-se ao contato com profissionais como bom ou ótimo, havendo uma paciente que se queixou de ter sido maltratada numa das enfermarias. Nenhum paciente manifestou o desejo de não ser examinado por estudantes. A "aula em volta do leito" foi o único aspecto referido como ruim ou regular por três pacientes, que se queixaram de não compreenderem o que era falado. Um paciente afirmou que se sentia como um "bicho em uma gaiola", mas ainda assim qualificou a internação como boa.

Quando questionados sobre eventos desagradáveis que possam ter ocorrido, uma paciente retomou a queixa de ter sido maltratada por profissionais da enfermaria e uma outra contou do óbito de uma mulher que estava em seu quarto - o que a deixou com muito medo de sua própria morte.

Indagados sobre o que poderia ser feito para melhorar o período de internação, espontaneamente se queixaram do tempo "que não passa", solicitando atividades para realizar enquanto estão na enfermaria. Quando as perguntas se dirigiram explicitamente às condições de hotelaria e relacionamento com pessoal, referiram problemas relacionados à manutenção e ao barulho na enfermaria no período noturno, nada afirmando sobre o relacionamento com a equipe.

Entre os entrevistados, quatro sujeitos não foram capazes de lembrar o nome de nenhum dos profissionais, aqui incluídos todo o corpo de enfermagem, médicos e alunos, embora fossem capazes de fornecer outras informações de maneira correta.

\section{DISCUSSÃO}

Uma possível limitação deste estudo diz respeito aos locais escolhidos para o grupo focal e as entrevistas. Foram realizadas nas duas maiores enfermarias do hospital, tornando plausível a hipótese de que os pacientes tivessem maior dificuldade para se lembrar dos nomes dos profissionais em função do maior número de profissionais e do revezamento entre os mesmos. Do mesmo modo, a realização do grupo focal apenas na enfermaria cirúrgica limitou os relatos apenas àqueles internados nesta enfermaria e, embora em ambas haja grande contingente de profissionais, não é possível afirmar o que teriam dito os pacientes da enfermaria clínica deste hospital.

Embora as avaliações dos pacientes tenham sido, em geral, positivas, dois fatos merecem destaque. O primeiro é a avaliação que os pacientes fazem da "aula em volta do leito" - único item não unanimemente avaliado como bom ou ótimo. É possível que sentimentos de gratidão pelo atendimento levem a superar situações desagradáveis às quais os pacientes foram expostos. Esta hipótese explicaria como, por exemplo, o paciente que referiu se sentir como um bicho na gaiola durante a visita médica ainda assim a classificou como boa e necessária. Como discutido por Rocco ${ }^{7}$, a obtenção dos dados a partir dos questionários e não no grupo focal também pode ter influenciado, já que há diferenças expressivas nas afirmações quando utilizado um ou outro método. Do mesmo modo, o fato de o procedimento cirúrgico ter sido bem-sucedido pode ter influenciado a avaliação que os pacientes fizeram de sua internação em sua totalidade, sendo a cirurgia um evento que marcaria toda a internação.

A respeito das visitas em hospitais universitários, Brescia e Quayle ${ }^{12}$ em estudo com 20 pacientes internados na Clínica Vascular do Hospital das Clínicas da USP, encontraram resultados semelhantes. Nesse estudo, a maior parte dos pacientes qualificou a visita como boa, mas acrescentaram comentários negativos a essa avaliação, como, por exemplo: "há falta de compreensão", "há falta de informação para o paciente" e "sentir-se como cobaia, objeto de estudo".

Brescia e Quayle ${ }^{12}$ lembram as recomendações do Cremesp quanto ao assim chamado "paciente didático", que sugerem:

Aos médicos, professores e estudantes que, durante suas preleções, aulas ou observações, abstenham-se de comentários além dos exigidos para obtenção dos dados anamnéticos e semióticos indispensáveis, reservando-se para, em separado, (proceder) à discussão do caso, diagnóstico diferencial, hipóteses diagnósticas, terapêutica e prognóstico, além das considerações supracitadas, a fim de evitar o constrangimento que tal prática possa acarretar. 
O mesmo trabalho sugere diretrizes técnicas de como conduzir a visita, respeitando seus aspectos didáticos, para alunos e residentes, e assistenciais, para o paciente.

Boulos ${ }^{13}$ afirma: "O treinamento médico envolve bem mais que a aquisição de novos conhecimentos. Envolve a compreensão de regras sobre sentimentos, erros e manuseio de nossas falhas...". O autor alerta para o risco de investir tempo e energia na transmissão do conhecimento médico, sempre crescente, e desencorajar o aprendizado humanístico da relação médico-paciente. Este último seria fruto da modelagem cotidiana nos cenários de ensino.

A segunda questão a ser destacada é o fato de quatro pacientes não terem sido capazes de citar o nome de nenhum dos profissionais ou alunos responsáveis por seus cuidados durante a internação. Martins ${ }^{14}$ afirma:

Em razão do acelerado processo de desenvolvimento tecnológico em Medicina, a singularidade do paciente - emoções, crenças e valores - ficou em segundo plano; sua doença passou a ser objeto do saber reconhecido cientificamente. $\mathrm{O}$ ato médico, portanto, se desumanizou.

Ainda a respeito desta despersonalização, Fernandes ${ }^{15}$ afirma que também a subjetividade do médico foi abolida, sendo este, hoje, apenas um porta-voz da instituição médica.

Caprara e Franco ${ }^{16}$, em extensa revisão sobre o tema, apresentam relatos de médicos que descreveram suas experiências na condição de pacientes. A partir destes relatos, os autores afirmam que há uma "sistemática despersonalização que se vive quando se é paciente. As próprias vestes são substituídas por roupas brancas padronizadas e, como identificação, um simples número".

Ao longo dos anos, referindo-se ao paciente pelos diferentes "codinomes" usuais na prática médica ("fígado do leito 15", "vesícula do leito 12"), intensificou-se o processo de despersonalização, e os profissionais, por sua vez, passaram a ser, eles também, "o doutor(a)" e o "enfermeiro(a)" anônimos, sem identidades. É imperativo lembrar que inúmeras vezes este processo de despersonalização na relação com o paciente configura um movimento defensivo do médico ao desgaste profissional ${ }^{17} \mathrm{e}$ às dificuldades encontradas no exercício da profissão.

Morinaga et al. ${ }^{18}$ observaram que médicos e pacientes, ao avaliarem a relação médico-paciente, escolhem atributos semelhantes desta relação como prioridade, entre elas a capacidade de comunicação. Tendo em vista este aspecto, alguns estudos procuraram avaliar a satisfação de pacientes com a comunicação estabelecida entre eles e seus médicos. Pereira e Azevedo ${ }^{19}$, em estudo conduzido em hospital universitário, observaram que 70\% dos pacientes não consideraram suficientes as informações recebidas durante sua internação. Ainda, para $64 \%$ deles a relação médico-paciente interferiu na evolução do caso.

Gulinelli et al. ${ }^{20}$ observaram que mais de $90 \%$ dos sujeitos internados em hospital universitário desejavam receber informações de patologias graves, como câncer ou aids, e também mais de 75\% desejavam que suas famílias fossem informadas. Os autores concluíram que informar pacientes e familiares sobre seus diagnósticos e opções terapêuticas é uma habilidade e atitude que deve ser enfatizada na formação médica. Grosseman e Patrício ${ }^{21}$ desenvolveram um estudo em Florianópolis no qual entrevistaram médicos sobre diferentes aspectos do seu trabalho. Nesse estudo qualitativo, diversos temas emergiram dos relatos dos profissionais, em especial a interação com seus pacientes, que, segundo concluíram os autores, não tem sido priorizada na formação médica.

Dificuldades de comunicação podem tornar a relação médico-paciente insatisfatória, com inúmeras implicações, inclusive jurídicas. Analisando os processos contra médicos que chegam aos conselhos estaduais de Medicina, Oselka ${ }^{22}$ afirmou que "grande parte jamais teria que chegar lá se tivesse havido uma conversa...". Para que se resgate a humanização na formação médica, é necessário recuperar aspectos tão simples e ao mesmo tempo tão fundamentais como médico e paciente se conhecerem pelo nome.

\section{CONSIDERAÇÕES FINAIS}

No presente estudo, embora tenham avaliado majoritariamente sua internação e a relação com profissionais como boa e ótima, os pacientes apontaram direções em que é possível aprimorar o cuidado prestado, como, por exemplo, na realização da visita médica, a respeito da qual foi observada certa ambivalência. Tratando-se de um hospital "universitário" e, portanto, de um espaço de aprendizagem, a melhora do cuidado prestado aos doentes poderá trazer melhoras para o ensino prestado. Colocando professores, alunos e pacientes para se relacionarem simultaneamente, a visita médica se apresenta como um paradigma de toda a interação entre estes atores, sendo um espaço pedagógico privilegiado por poder envolver os três aspectos centrais do ensino médico: habilidades, atitudes e cognição. Diretrizes que norteiem sua realização devem ser estabelecidas para que ela preserve seu papel didático sem constrangimentos para o paciente.

Estratégias institucionais de avaliação contínua são necessárias, especialmente em serviços universitários, pois nestes locais é que serão forjados os futuros profissionais de saúde. Nestas avaliações devem ser aliadas metodologias quantitati- 
vas e qualitativas - estas últimas, mais apropriadas para captar o fenômeno da interação humana, aquilo a que se resume, enfim, a relação entre médicos, alunos e pacientes.

\section{REFERÊNCIAS}

1. Jeammet P, Reynaud M, Consoli S. Manual da Psicologia Médica. Rio de Janeiro: MEDSI; 2000.

2. Brasil. Ministério da Educação. Secretaria de Educação Superior. Diretrizes Curriculares Nacionais do Curso de Graduação em Medicina. Brasília (DF): Ministério da Educação e Ministério da Saúde; 2001.

3. Coulehan J, Block M. A Entrevista Médica. Porto Alegre (RS): Artes Médicas; 1989.

4. Lima MCP. O Psicodrama e o Ensino da Relação médico Paciente: reflexões a partir de uma Experiência Prática. Rev Bras Psicodrama. 1997; 5: 11-9.

5. Pedroso ERP. Os Desafios da Clínica e do clínico: Para onde vai a Clínica neste século? Rev Med Minas Gerais. 2001; 11:116-21.

6. Troncon LEA. A importância das características pessoais dos estudantes de Medicina na sua educação. Rev Bras Educ Med. 1995; 19:7-11.

7. Rocco RP. Relação estudante de Medicina-paciente. In: Mello Filho J. Psicossomática Hoje. Porto Alegre (RS): Artes Médicas; 1992. p. 45-63.

8. CREMESP. Guia de Relação Médico Paciente. São Paulo: Conselho Regional de Medicina do Estado de São Paulo; 2001.

9. Scharamm, DR. Bioética e Educação Médica - Buscando Respostas aos Dilemas morais da prática em Saúde. Boletim ABEM. 2000; 28:8-13.

10. Kitzinger J. Qualitative Research: Introducing focus groups. BMJ 1995; 311:299-302.

11. Hennekens CH, Buring JE. Epidemiology in Medicine. London: Little Brown and Company; 1987.

12. Brescia S, Quayle J. A Percepção do Paciente em relação à visita médica num hospital-escola: um estudo exploratório. Rev Bras Educ Med. 1997; 21:39-46.

13. Boulos M. Relação Médico-Paciente: o ponto de vista do clínico In: Marcondes E e Gonçalves EL, organizadores. Educação Médica. São Paulo: Savier; 1998. p. 50-7.

14. Martins MCFN. Humanização na Saúde - relação médico paciente no microscópio. Rev Ser Médico. 2002; 18:27-9.

15. Fernandes JCL. A quem interessa a relação médico-paciente? Cad Saúde Pública. 1993; 9:21-7.
16. Caprara A, Franco ALS. A relação paciente-médico: para uma humanização da prática médica. Cad Saúde Pública. 1999; 15:647-54.

17. Nogueira-Martins LA, Nogueira-Martins MCF. O exercício atual da medicina e a relação médico-paciente. Rev Bras Clin Terap. 1998; 24:59-64.

18. Morinaga CV, Konno SN, Aisawa RK, Vieira JE, Martins MA. Frases que resumem os atributos da relação médicopaciente. Rev Bras Educ Med. 2002; 26:21-7.

19. Pereira MGA, Azevedo ES. A relação médico-paciente em Rio Branco/AC sob a ótica dos pacientes. Rev Assoc Med Bras. 2005; 51(3):153-7.

20. Gulinelli A, Aisawa RK, Konno SN, Morinaga CV, Costardi WL, Antonio RO, Dumarco RB, Moino RM, Katz M, Giavarotti S, Skarbnik APZ, Forcione CS, Chiba T, Martins MA. Desejo de informação e participação nas decisões terapêuticas em caso de doenças graves em pacientes atendidos em um Hospital Universitário. Rev Assoc Med Bras. 2004; 50(1):41-7.

21. Grosseman S, Patrício ZM. A relação médico-paciente e o cuidado humano: subsídios para promoção da Educação Médica. Rev Bras Educ Med. 2004; 28(2):99-105.

22. Oselka G, Segre M, Castilho JR, Sztarn R. Ética médica para o século 21 (debate). Diálogo Médico. 2002; p. 40-5.

\section{Conflito de Interesses}

Declaramos para os devidos fins que o artigo "Percepção de pacientes sobre a internação em um Hospital Universitário: implicações para o Ensino Médico" não contou com qualquer tipo de apoio financeiro para sua realização. Maria Cristina Pereira Lima e Irio José Gonçalves são professores da Faculdade de Medicina de Botucatu. À época da coleta dos dados a Dra. Andréa Christina Cortopassi era acadêmica da mesma instituição, sendo que, atualmente é residente do Programa de Ortopedia e Traumatologia.

\section{Endereço para correspondência}

Maria Cristina Pereira Lima

Departamento de Neurologia e Psiquiatria

Faculdade de Medicina de Botucatu

Rubião Junior, s/n ${ }^{\circ}$

18618-000 - Botucatu - SP

E-mail: mclima@fmb.unesp.br 


\section{QUADRO 1}

Roteiro utilizado para entrevista semi-estruturada conduzida junto a pacientes internados nas enfermarias clínica e cirúrgica

1. $\mathrm{O}(\mathrm{A})$ senhor(a) está de alta. Como foi o período de internação?

2. Durante a estada no hospital podem acontecer coisas boas e ruins. O que o senhor diria que aconteceu de bom?

3. Durante a estada no hospital podem acontecer coisas boas e ruins. O que o senhor diria que aconteceu de ruim?

4. Quantas vezes o senhor foi entrevistado ou examinado por estudantes?

5. Estes estudantes se apresentaram para o senhor?

6. O senhor lembra o nome de algum deles?

7. Como foi para o senhor receber estes estudantes que vinham ao seu leito para conversar/aprender a examinar? Por quê?

8. Como o senhor acha que foi para os estudantes virem ao seu leito para conversar/aprender a examinar?

9. Os estudantes pediram permissão para conversar ou examinar o senhor?

10. Quantas vezes o senhor disse que não gostaria de ser examinado ou conversar naquele momento?

11. Quantas vezes o senhor foi examinado apesar de não ter permitido?

12. Alguma vez os médicos deram aula para os estudantes em volta de sua cama? Se sim, como foi esta experiência para o senhor?

13. O senhor sabe o nome das pessoas que cuidaram do senhor nesta internação? (anotar todos os nomes e a função descrita pelo paciente).

14. O senhor está de alta. O senhor acha que entendeu tudo sobre sua doença ou ainda tem dúvidas? (perguntar nome da doença, tratamento proposto, retornos marcados)

15. Durante esta internação, em algum momento o senhor acredita que foi desrespeitado por alguém?

16. Na sua opinião, o que poderia ser feito para melhorar a estadia de quem fica internado neste hospital?

17. Há alguma coisa a mais que o senhor gostaria de falar sobre esta internação? 